\title{
O GRAMÁTICO CELSO CUNHA: A LÍNGUA PORTUGUESA UNA NA DIVERSIDADE
}

\author{
Maria Helena de Moura NEVES*
}

- RESUMO: Esta incursão na obra de Celso Cunha destaca tensões que o autor logra estabelecer e conciliar em suas obras linguístico-filológicas, movendo-se em uma noção que, sem conformismo e sem nacionalismo, decorre de sua proposta de que o destaque da "norma culta" (das "finuras e sutilezas" da língua) convive tranquilamente com o destaque da preeminência da língua falada. Fica equacionada essa convivência - singular, para o panorama da época - na proposta de uma ação escolar que ofereça ao aluno experiências "edificadoras" para a apreensão do "dialeto prestigioso", sem lhe pedir o abandono do vernáculo (e salvaguardada a atenção à adequação de registro). Nessa direção, o que este artigo ressalta, na sua espinha dorsal, é a proposta de que o trabalho escolar com a gramática se conduza exatamente pela noção de que uma língua é necessariamente "una na diversidade", dado que, cientificamente, qualquer língua natural tem como estatuto, rigidamente, ser "una”, entretanto na necessária pluralidade dos usos (modos de expressão). Decorre, dentro desse edifício de tensões conciliadas, que, para Celso Cunha, todos somos "condôminos do idioma"; e dadas as incumbências sugeridas por ele para o trabalho com a língua, entende-se que temos de ser naturais zeladores desse patrimônio comum.

- PALAVRAS-CHAVE: Língua natural; norma culta; unidade linguística; diversidade linguística; gramática escolar.

\section{Introdução}

Este artigo começa recuperando um texto escrito sob encomenda do Caderno Mais, da Folha de S. Paulo (NEVES, 2004), a propósito de dois livros históricos que saíram publicados na mesma época, ambos com a significativa chancela da Academia Brasileira de Letras. Neles vinham a lume “dispersos” e alguns inéditos de dois estudiosos que fizeram história na construção do saber linguístico e filológico no Brasil: Antenor Nascentes e Celso Cunha. Eram:

\footnotetext{
* Universidade Presbiteriana Mackenzie (UPM), Centro de Comunicação e Letras, São Paulo - SP - Brasil. Universidade Estadual Paulista (UNESP). Araraquara - SP - Brasil. mhmneves@uol.com.br. ORCID: 0000-0003-4667-2657.
} 
- a coletânea Estudos filológicos de Nascentes (2003), organizada por Raimundo Barbadinho Neto (com apresentação e orelha de Evanildo Bechara e com quarta capa de Celso Cunha), pertencente à coleção "Antônio de Morais Silva-Estudos de Língua Portuguesa", dirigida por Evanildo Bechara;

- a obra de homenagem a Celso Cunha, Sob a pele das palavras (2004), organizada por Cilene da Cunha Pereira (sua filha, e pesquisadora), com trinta ensaios desse grande filólogo e linguista, bibliófilo e medievalista, literato e camonista, divididos em cinco seções: Medievalística, Camonística, Lexicografia (na maioria dos casos, Metalexicografia, ou Lexicologia), Filologia e Linguística, Memorialística.

São duas memoráveis obras de homenagem, material valioso para uma área a historiografia linguística - que, felizmente, vem tomando grande impulso, na incorporação que tem havido de gente nova, da Linguística, que se soma aos mestres filólogos. Vieram elas do Rio de Janeiro, de onde temos visto vir o grande estofo da cultura filológica brasileira, embalada no berço do Colégio Pedro II. Feliz memória a de quem tem na sua história um colégio que registra concursos para os quais um candidato manda buscar na Europa livro que trata "do problema das nasais no português antigo", que foi o que fez Antenor Nascentes, segundo o depoimento do embaixador Roberto Assumpção de Araújo, na página XLIV do livro-homenagem a que aqui já se fez referência.

Do exame de ambas as obras e da reflexão a que elas levam - dizia o artigo do "Caderno Mais" - fica, afinal, a nítida noção de que muitos dos afoitos que hoje ingenuamente assestam baterias, a torto e a direito, contra o bloco de conhecimento sobre língua e linguagem que a tradição oferece, com certeza ouviram falar alguma coisa sobre gramáticos tradicionais e sobre filólogos do século passado, mas não leram, realmente, as lições que os grandes dentre eles nos dão.

Sobre Celso Cunha dizia o texto que quem é esse autor na história da Linguística e da Filologia qualquer estudioso do ramo sabe, admirando a figura. Também que quem buscou estudar a fundo esta língua portuguesa, por qualquer filtro, o teve à cabeceira. $\mathrm{E}$, ainda, que o povo brasileiro - o povão -, de norte a sul, também conhece e respeita esse nome que é o de um gramático de rigor tradicional mas de sensibilidade inovadora, em quem se agarram tanto os tradicionalistas convictos, que confiam no seu estabelecimento de padrões gramaticais, quanto os inovadores ferrenhos, que também nele confiam para lições cientificamente alicerçadas, por exemplo até sobre "variação linguística" (uma bandeira dos nossos dias, quando se quer apregoar modernidade e cientificidade).

Lembrava também o artigo que nosso gramático já recebera uma homenagem memorável na publicação da Miscelânea de estudos linguísticos, filológicos e literários in memoriam Celso Cunha, na qual Houaiss (1995, p.LV) no mesmo sentido, a ele se referia como "apaixonado da luta pela unidade da língua e por isso esforçado no estabelecimento de suas variantes e eventuais contrastes, no plano empírico e no de 
uma política comum da língua". Vinha acentuado, ainda, que o conjunto de textos que então se publicava só fazia confirmar a posição que Josué Montello (1995, p. LVII, grifo do autor) atribuiu, relevantemente, a Celso Cunha: a do "grande mestre que, conhecendo profundamente a língua portuguesa, nas suas minúcias e no seu conjunto, associou a esse saber admirável a sensibilidade de quem nascera para apreciá-la na condição de obra de arte". E esse é um ponto a que este artigo voltará, dando-lhe a importância devida.

Eram bem-vindos, particularmente, os inéditos, entre os quais foi destacado o delicioso e intrigante A magia da palavra (PEREIRA, 2004). Esse texto tem de notável a sua organização, a qual se faz ver claramente como provisória, e, por isso mesmo, como reveladora de uma capacidade singular de pontilhar um tema e ao mesmo tempo mergulhar nele, só possível a alguém com a formação, a curiosidade e a experiência reconhecidas no autor. O tema da "linguagem como magia" se desnuda, aí, num acercamento que vem de diversos ângulos. Parte o estudo da afirmação de que pela palavra "fomos criados" (PEREIRA, 2004, p. 217), para, daí, ir aos nomes próprios um campo que exige tratamento guiado por muita reflexão e sensibilidade - chegando, então, ao mistério do silêncio, não sem antes fixar-se no crescer de um primado da escrita, terreno em que não é de esquecer Platão (que, aliás, nosso gramático nunca deixa esquecido).

E assim, temos, até aqui, uma moldura para trazer à reflexão esse pensador da linguagem que é Celso Cunha, um filólogo que (avançadamente) faz gramática à luz da Linguística (com atenção para os grifos que aqui se registram).

E a moldura agora se estreita para criar focos de tensão dentro dos quais a produção plural de Celso Cunha se instala. Essa produção vai ser aqui referida por apenas quatro obras, bastante representativas, separadas em dois conjuntos (que serão desenvolvidos a seguir em duas partes). Propõe-se que cada um deles se define por um tipo de tensão particular - o primeiro mais sustentado na Linguística, o segundo mais sustentado na Filologia -, ambos reduzindo-se à tensão central entre unidade idiomática e diversidade linguística ${ }^{1}$, entretanto ambos desenvolvidos por um pensador que nunca abre mão do tradicionalismo para a sua visão da expressão linguística na comunidade. No primeiro conjunto (próxima seção) o viés sociopolítico conduz as questões, e no segundo conjunto (seção subsequente) o viés socioeducacional conduz as questões:

(i) o viés sociopolítico traz a tensão entre norma portuguesa e realidade brasileira;

(ii) o viés socioeducacional traz a tensão entre norma (culta) contemporânea (de expressão oral e escrita) e padrão de uso nesse momento de evolução da língua.

Atente-se para o substantivo idioma - não língua -, o qual Celso Cunha (1975, obra adiante comentada) define como a "língua histórica" - por exemplo, "a língua portuguesa, a língua espanhola, a língua francesa" -, em oposição à "língua funcional". 


\section{O viés sociopolítico da questão: Norma portuguesa versus realidade brasileira. Ou: servilismo versus nacionalismo linguístico.}

Um fato significativo a apontar é o de Celso Cunha colocar-se explicitamente como propositor de uma "política do idioma" (CUNHA, 1975)2.

No prefácio que faz a essa $3^{\text {a }}$ edição da obra, Aires da Mata Machado Filho retoma palavras com que havia saudado o livro em 1965: começa comentando a indicação que o próprio Celso Cunha faz sobre o modo pelo qual ele entende essa "política": para ele (CUNHA, 1975, p.9, grifo do autor), ela é "uma das muitas políticas que se podem adotar para o ensino da língua"- caracterizada como "singela, realista, que luta não por uma utópica unificação do idioma, mas por manter a sua unidade relativa" -, sabendo de antemão que, "considerada no tempo e no espaço, uma língua não pode ser tout à fait la même". Em continuação, o prefaciador lembra ainda este acréscimo do gramático: "queremos apenas que, de cada lado do Atlântico, a nossa não se torne tout à fait une autre".

O que ele defende é, exatamente, a existência de uma unidade que não toca a unificação: em vez disso, a unidade que ele prega confere identidade a cada uma das peças, exatamente o que se obtém pelo abrigo daquilo que não é idêntico em ambas. Cabe bem, assim, a expressão "inteireza na pluralidade", usada por Ivan Russeff (2003, p. 3) em comentário da obra.

Não se vai tratar, aqui, o revestimento propriamente político das manifestações de Celso Cunha, que Mata Machado discute como polemizante e crítico, especialmente quando faz a apreciação da condução histórica daquilo que o gramático denomina como "controle normativo" (CUNHA, 1975, p. 10) de nossa língua (do Brasil) por Portugal, o que remete à controvérsia sobre quem é o dono da língua comum. É dentro dessa questão que cabe ambientar a notável proposição de Celso Cunha $(1975$, p.42) de "condomínios políticos" de língua, no nosso caso presentificada no fato de sermos, Brasil e Portugal, "condôminos do idioma" (CUNHA, 1975, p. 41), digamos, parceiros pareados no uso natural do idioma português.

Permaneçamos ainda nessa questão geral para lembrar que, como sempre em seus exames, Celso Cunha vai à escolha dos textos com foco na lida escolar com a língua materna (adjetivo este que ele não usa). Obviamente entra, no caso, o papel da Filologia, cujo espectro, para consideração dos fatos da língua, com felicidade se soma a / se organiza com o espectro da ciência da linguagem - a Linguística -, cujas lições os nossos gramáticos denominados "tradicionais" (cito Evanildo Bechara e Celso Cunha como exemplos) têm conseguido mostrar. Diz textualmente Celso Cunha, na "Explicação" que apõe à $3^{\mathrm{a}}$ edição (CUNHA, 1975, p. 15, grifo do autor): "Procuramos

Observe-se que, em uma Explicação colocada nessa $3^{\text {a }}$ edição (1975), Celso Cunha adverte que o que estava como subtítulo da primeira reimpressão dessa obra (Para uma política do idioma) passa então a título (Uma política do idioma), porque era isso que - diz ele - "continha a ideia predominante do estudo" (CUNHA, 1975, p. 15). Atente-se novamente para a referência a idioma, não a língua. 
intencionalmente alinhar fatos e fundamentar nossas afirmações na boa doutrina dos linguistas e filólogos contemporâneos".

Pode-se interpretar que aí ele se põe, declaradamente, pela defesa de uma multiviesada condução científica de análise, mediante a consideração dos fatos de língua de tal modo feita que, no trato do ato de linguagem, haja nitidez de visão do sistema linguístico (levado em conta exatamente o caráter abstrato do sistema). Por outro lado, pode-se observar em Cunha (1975) uma defesa do indesmentível peso da cadeia histórica no estágio presente do fato linguístico em análise, defesa que, entretanto, não tem valor simplesmente por apostas de pura revivescência, com o que, aliás, se desmentiria o fato de que a língua tem real história. Isso vale também, como aponta Cunha (1975), no sentido contrário, que é o de querer ver fatos de outra época com os olhos da atualidade: ora, quem os produziu (e a referência do gramático vai aos “escritores") tinha os padrões linguísticos de seu tempo. Assim - como diz ele - esses escritores "insuflaram na expressão os ideais de seu tempo" (CUNHA, 1975, p. 23).

Em princípio, o que Celso Cunha põe em exame são, pois, exemplos, são tokens selecionados, referidos quase sempre diretamente como provindos de "escritores". Basta lembrar que, dos "escritores" (verdadeiros exemplos de uso da língua, ou seja, de escolha regida pelos padrões), Cunha (1975, p.26) chega a dizer coisas como: “[...] fazem até da impropriedade uso consciente, empregando-a como recurso de estilo de rara expressividade"; "Melhor que os filólogos, os escritores sentem"; "A maioria das incorreções (se há nos escritores) serve geralmente para prevenir e reparar os déficits da língua correta".

E, afinal, excluindo explicitamente da lida dos escritores (esses verdadeiros modelos) uma intenção de controle normativo da expressão (e criticando explicitamente os puristas), Cunha (1975, p. 28) pontifica: "um escritor purista é, pois, um escritor que se atém a formas de poesia inventadas por outros artistas de seu país: o que quer dizer que é um imitador, não um poeta".

E é por via da constante remissão aos escritores que se pode entrar na discussão de uma tensão - que Cunha (1968) considerava observável no tratamento do uso linguístico do português no Brasil - entre o que ele tinha como a "norma portuguesa" e aquilo que ele invoca como "realidade brasileira", afinal, duas normas que o autor configurava. Para isso, vai-se aqui, exatamente, pela obra Lingua portuguesa e realidade brasileira (CUNHA, 1968), em que com clareza são vistas, absolutamente configuradas, tanto a porção de linguista e de filólogo de Celso Cunha quanto a sua porção de gramático dedicado ao ensino escolar de língua (de que tratará a segunda parte deste artigo). Cabe adiantar que, em Celso Cunha, o ensino escolar se configura como aquele dirigido ao desempenho linguístico que seja atribuível a um brasileiro escolarizado, pois - fixada, aí, uma premissa - é desse padrão de língua que ele cuida quando se refere à "língua culta". Aí se encontra exatamente apontada uma tensão - observável no tratamento do uso linguístico do português no Brasil - entre aquilo que ele considera a "norma portuguesa" e aquilo que ele invoca como "realidade brasileira", afinal, duas normas assim configuradas: 
(i) a primeira ("norma portuguesa"), atracada à "pacificamente aceita" "ideia de que a Europa - e só ela - possuía, de direito, as matrizes de cultura";

(ii) a segunda (a "realidade brasileira"), inaugurada com aquela "indiscrição maior" que foi a "pena poderosa de José de Alencar".

Tudo isso vem com atenção para o fato de que a crítica que se encontra feita ao romântico Alencar é particularmente dirigida à sua "expressão linguística", não à sua temática de idealização do indígena (em que a questão de normatividade estaria ausente). É assim que, para Cunha (1968, p.15), já aí “os problemas de língua derivaram naturalmente para o conflito de paixões", um "conflito de preconceitos" entre "uma concepção fossilizada da língua" e um "anelo por uma língua nacional, própria, desvinculada da portuguesa", o que seria - e para alguns, hoje, ainda é - "um imperativo de nossa soberania" (CUNHA, 1968, p. 15-16). E o que nosso gramático discute, a propósito, é exatamente o conceito de língua própria, noção defendida, por exemplo, por Cassiano Ricardo, em relação a uma língua, o que Cunha (1968, p.15) considera um "jacobinismo linguístico". Citando Amado Alonso, diz ele que essa ideia de língua própria se deve a um equívoco. De fato "os bens anotáveis no registro da propriedade são próprios de um quando não o são dos demais"; entretanto, a língua não é desse tipo de bens: ao contrário, ela é daqueles bens que "são maiores quanto mais comunicados, como diziam os homens do Renascimento": "uma língua é própria de uma nação quando é $a$ que as crianças aprendem de seus pais [...] e $a$ que seus poetas e prosadores elaboram e cultivam esteticamente para suas produções de alta cultura" (CUNHA, 1968 , p. 16, grifo do autor).

Isso que Amado Alonso teoriza tão certeiramente fica colocado por Cunha (1968) naquele conflito - a que todos nós temos assistido na nossa lida com a questão do português brasileiro - entre "o reacionismo historicista e o jacobinismo nacionalista" (CUNHA, 1968, p. 18), o que ele atribui, explicitamente, a "certos filólogos (alguns deles eminentes)", no seu "exame das diferenças linguísticas entre o português europeu e o americano". O problema, diz Celso Cunha, está em que conclusões válidas só podem ser tiradas se o que se compara são "termos relacionáveis" (CUNHA, 1968, p.18), e não é o que tem acontecido; lucidamente, ele diz: “opõe-se, de regra, a língua comum de Portugal aos falares das classes humildes do campo e das cidades do Brasil" (CUNHA, 1968 , p. 18), e, por aí, como não podia deixar de ser, chega-se a "diferenças profundas em todos os domínios" (CUNHA, 1968, p. 18), ficando inadvertida a "superior unidade não só da língua literária, mas também da língua falada pelas classes cultas nos dois países" (CUNHA, 1968, p. 18-19). Tudo porque ficam em "esquecimento frequente" "traços comuns, sem dúvida os preponderantes" no uso (CUNHA, 1968, p. 18, grifo do autor).

E por aí se entra nessa noção - extremamente relevante dentro da visão de Celso Cunha da "realidade brasileira" do uso do português - de modalidade "culta" da língua, um centro marcante da atenção do nosso gramático. Assim, continuamente é à língua 
considerada "culta" de cada ponto geográfico em questão - Brasil e Portugal - que ele vai[?], para defender que são dois os fatos a considerar (CUNHA, 1968):

(i) as “sensíveis diferenças da língua popular” (CUNHA, 1968, p. 19);

(ii) e a "relativa coesão da língua culta" (CUNHA, 1968, p. 19) de um e de outro lugar geográfico, político e cultural.

Como mostra Cunha (1968), facilmente se recupera, na história de nossa colonização, “de um lado, uma língua popular, entregue à sua sorte na boca de tantas e tão variadas comunidades de analfabetos que se espalhavam pela imensidão do Brasil, e, de outro, a língua dos doutores e dos padres, dos bacharéis bem falantes [...]" (CUNHA, 1968, p. 20$)^{3}$.

Aí está a grande bandeira de Celso Cunha: a defesa de um reconhecimento de variação e de mudança na língua, mas não com aquele nacionalismo que levanta a defesa da legitimação de uma concessão libertária ao popular ou ao não regrado, e sim com uma centração na denominada "língua culta" (que, afinal, para ele, é a língua dos literatos).

As palavras de Machado de Assis (que constam, segundo indicado, de um artigo publicado em 1873 (que vem sem referência bibliográfica) são lembradas por Cunha (1968, p. 25) para afirmar que, sem dúvida, "as línguas se aumentam e se alteram com o tempo e as necessidades dos usos e costume" e que "querer que a nossa língua pare no século de quinhentos é um erro igual ao de afirmar que a sua transplantação para a América não lhe inseriu riquezas novas". Muito relevantemente, o que está aí não é a pregação viesada de um populismo libertário, como se tal verdade fosse apenas bandeira para a tolerância ou até a boa aceitação de usos que a norma prescritiva indicaria como desvios. Pelo contrário, basta ir ao final do trecho para verificar que tais mudanças linguísticas estão aí defendidas para contabilizar, também, ganhos, até de estilo. Ainda citando: "Há, portanto, certos modos de dizer, locuções novas, que de força entram no domínio do estilo e ganham direito de cidade" (CUNHA, 1968, p. 25). E aí está a invocação de estilo, para comprovar a noção pela qual Celso Cunha se mantém na priorização da linguagem que brota daquela criação descompromissada dos escritores.

Nada, portanto, do que Cunha (1968) defende como legitimação de variação e mudança se instala na defesa de uma legitimização de perdas sociopolíticas e culturais (uma degradação): não há nenhum empenho dele em defender a "correção idiomática" (CUNHA, 1968, p. 35) pura e simplesmente pela correção em si e por si, ou seja, não há nenhuma concessão a "terrorismo purista" (CUNHA, 1968, p. 27), a "prescritivismo gramatical" (CUNHA, 1968, p. 35), nenhum resguardo de "purismo" (CUNHA, 1968, p. 15), ou "pureza idiomática" (CUNHA, 1968, p. 29).

\footnotetext{
3 Em parêntese aponte-se que Celso Cunha faz uma ressalva, invocando o contraste com a colonização espanhola da América. Assim, fazendo uma concessão, ele observa: embora "a colonização portuguesa, com inúmeros saldos positivos", não tenha sido "exemplar no terreno educacional e cultural” (CUNHA, 1968, p. 20), pois "só no século XIX tivemos o primeiro estabelecimento de ensino superior" (CUNHA, 1968, p. 19-20).
} 
A bandeira que aqui se põe na mão de Celso Cunha é a do teórico de uma sociolinguística não canônica, a qual, de certo modo, prescinde da discussão das alterações ligadas à popularização do idioma e abstrai da legitimação delas. Nessa bandeira propõe-se, aqui, incluir a especial atenção que o gramático dá à língua falada, a qual, nesse contexto - e é o notável -, permanece exatamente dentro da visão da "língua culta": aliás, o que está posto em questão (dado o objetivo central de oferecer uma proposição de obra gramatical que vá à escola) é preservar essa instituição como o lugar ao qual compete - em pregação assumida - o "resguardo" da "unidade" da língua; mais especificamente (e significativamente): da "unidade superior" da língua portuguesa (CUNHA, 1968, p. 72).

Celso Cunha prega continuamente o imperativo de resguardo dessa "unidade superior" do idioma, entretanto apregoando, ao mesmo tempo, a necessidade de a língua renovar-se (CUNHA, 1968, p. 31). Não se trata de unificação, não se trata de uniformização, trata-se, sim, de resguardo da manutenção de um padrão de língua de escolarizados, o qual - abstrato que é, como todo padrão - passa longe tanto da consideração de um libertarismo nacionalista (em termos de expressão linguística) quanto da consideração de um terrorismo purista (em termos da ação sobre o desempenho linguístico).

É citando Coseriu (1958, p. 31), com seus vários "sistemas” e suas várias “normas", que Cunha (1968) vai ao que aqui vem referido como padrão para a visão de (retomando) "unidade superior" da língua:

Se uma língua pode abarcar vários sistemas, ou seja, as formas ideais de sua realização, a sua dinamicidade, o seu modo de fazer-se, pode também admitir várias normas, que representam modelos, escolhas que se consagraram dentro das possibilidades de realizações de um sistema linguístico. (CUNHA, 1968, p. 73).

Daí se passa, naturalmente, ao ensino escolar, assinalando-se que até aqui se quis assentar, por parte de Celso Cunha, a firme tomada de posição de uma política da língua que guia toda a sua condução de uma "gramática escolar".

\section{O viés socioeducacional da questão: A norma (culta) contemporânea de expressão oral e escrita versus o momento atual de evolução da língua. Ou: manutenção de padrão versus inovação de uso.}

E é nessa nova moldura que se vai ao conjunto da obra especificamente gramatical de Celso Cunha ${ }^{4}$, isto é, àquela que foi preparada por ele para ir à escola. Pode-se começar

4 Citem-se: Gramática do Português Contemporâneo (1 $1^{\mathrm{a}}$ edição Belo Horizonte, 1970), de que emanaria a Nova Gramática do Português Contemporâneo, escrita em colaboração com Lindley Cintra e publicada, em Lisboa, em 1984, e no Rio, em 1985; Gramática da língua portuguesa, publicada pelo Ministério da Educação (1a edição Rio, 1972). 
com sua indicação, feita na inaugural Gramática do português Contemporâneo (1970), cujo objetivo declarado é "apresentar as características do português contemporâneo em sua forma culta" assim como os "fatos da linguagem coloquial" (CUNHA, 1970, p. 9, grifo do autor, chamando a atenção para o abrigo daquela mesma "tensão", novamente escancarada). Mais: para exemplificar os usos, diz o autor que se utiliza de textos de “escritores brasileiros e portugueses do Romantismo para cá, dando naturalmente uma situação privilegiada aos autores de nossos dias (1969)" (CUNHA, 1970, p. 9). Trata-se da assunção de "um claro conceito de norma e correção" (CUNHA, 1970, p. 10, grifo do autor), indispensáveis, segundo o autor, para uma gramática descritiva da língua culta. E insista-se em que aí está o conceito linguístico de norma que colhe lições de Coseriu (já citado em Cunha, 1970, p. 13), o qual, dentro de uma via funcionalista, corresponde àquilo "que já se disse e tradicionalmente se diz na comunidade considerada" (CUNHA, 1970, p. 13).

Mas, assentado esse finca-pé básico (de condução teórica) na funcionalidade dos conceitos que sustentam as propostas, cabe conduzir as reflexões no sentido de verificar a direção prática da obra gramatical de Celso Cunha, e, aí, o que se entende é que a verificação possa ir, mais lucrativamente, pela última obra gramatical produzida, que é a difundidíssima Nova Gramática do Português Contemporâneo (CUNHA; LINDLEY CINTRA, 1985). Lá se declara que a intenção foi criar uma gramática que servisse de "guia orientador de uma expressão oral e escrita que, para o [então] presente momento da evolução da língua, se pudesse considerar correta" (CUNHA; LINDLEY CINTRA, 1985 , p. xiii, grifo do autor). No primeiro capítulo, explicita-se o que se entende por "correto" indicando-se: "a norma pode variar no seio de uma mesma comunidade linguística", e portanto, "este conceito de norma, que implica um maior liberalismo gramatical, é o que, em nosso entender, convém adoptarmos para a comunidade de fala portuguesa (...)" (CUNHA; LINDLEY CINTRA, 1985, p. 8, grifo do autor). E literalmente se acrescenta (atente-se): "Com efeito, por cima de todos os critérios de correção - aplicáveis nuns casos, inaplicáveis noutros - paira o da aceitabilidade social, a consuetudo de Varrão, o único válido em qualquer circunstância." (CUNHA; LINDLEY CINTRA, 1985, p. 8)

Não existe, entretanto, na obra, um movimento que conduza socialmente a instruções de confinamento da expressão, o que, aliás, agrediria a concepção central de Celso Cunha da necessidade de oferecimento de textos em que esteja registrado o modo de expressão linguística criativa, que é justamente aquilo que faz dos escritores a referência de uso nas suas obras gramaticais. Lembre-se, a propósito, que o que ele propõe no seu Língua portuguesa e realidade brasileira, de que aqui se tratou na Parte 1., são "medidas práticas, baseadas na realidade linguística dos dois países" (CUNHA; LINDLEY CINTRA, 1985, p. 68, grifo do autor), as quais - pode-se dizer, concluindo mais persuadem, na direção da norma "culta" vigente em cada país, do que constroem artificialmente padrões convencionais de uso.

Na essência: Na Gramática do português Contemporâneo (1970) Celso Cunha já diz que seu objetivo é apresentar as características do português contemporâneo em sua 
forma culta, e os fatos da linguagem coloquial. Para exemplificar os usos, o autor se utiliza de textos de "escritores brasileiros e portugueses do Romantismo para cá, dando naturalmente uma situação privilegiada aos autores de nossos dias". Trata-se, pois, de uma proposta de gramática fundada em "um claro conceito de norma e correção" (CUNHA, 1970, p. 9), indispensáveis, segundo o autor, para uma gramática descritiva da língua culta. Entenda-se, porém, que o conceito linguístico de norma adotado é aquele de Eugenio Coseriu, que corresponde "ao que já se disse e tradicionalmente se diz na comunidade considerada" (COSERIU, 1973 apud CUNHA; LINDLEY CINTRA, 1985, p. 8).

\section{Conclusão}

Estas reflexões desembocam justamente na obra $A$ questão da norma culta brasileira (CUNHA, 1985, p. 47), na qual esse título de referência explícita à "norma culta" convive com um destaque muito forte da língua falada, proposta absolutamente singular no panorama da época, mas não de estranhar nesse gramático, que, como aqui se indicou, na sua Gramática do português contemporâneo (1970) já estabelecera como objetivo apresentar as características do português contemporâneo em sua forma culta juntamente com os fatos da linguagem coloquial, sempre com visita aos "escritores", especialmente os daqueles "dias” (CUNHA, 1970, p. 9).

Cunha (1985) defende explicitamente a conveniência de que ao aluno das escolas sejam dadas condições (sempre edificadoras) para que ele "se assenhoreie progressivamente do dialeto prestigioso sem que seja violentado com a desorganização ou a destruição de seu vernáculo", afirmação que vem acompanhada da ressalva de que desse vernáculo o aluno "continuará a servir-se nas suas situações mais íntimas" (CUNHA, 1985, p. 47).

Afirme-se que, para a avaliação desse gramático, que, em meados do século XX, já levanta a (tensa) bandeira da "língua una na diversidade", vale o que diz Aires Mata Machado Filho em seu Prefácio de Uma política do idioma. O que ele depurou da proposição de Celso Cunha para uma gramática escolar está, entretanto, nesta sua afirmação: "das finuras e sutilezas da língua não deviam descurar os professores, como acertadamente adverte [Celso Cunha]" (CUNHA, 1975, p. 11).

$\mathrm{O}$ que se quer ressaltar nesta revisão do papel de Celso Cunha na história da condução escolar da visão da gramática é a pregação de um cuidado com a língua portuguesa - material de reflexão e de análise do autor - por via da pregação de um esforço de manutenção da unidade na diversidade, e por dois ângulos de visão: tanto a defesa da unidade como a defesa da pluralidade vêm assentadas em uma concepção da ciência linguística do que seja uma língua natural (e, derivadamente, uma língua nacional): una, entretanto reconhecida como plural. O ângulo é, pois, a defesa da pluralidade de modos de expressão (a pluralidade de normas) em uma nação. Entra aí, legitimamente e relevantemente, a variação pelo lugar da fala e a variação pela 
caracterização do falante; a primeira (variação diatópica), representada na circulação da língua em mais de uma nação (com o olhar dirigido mais centralmente para Brasil e para Portugal, que é a metrópole histórica); e a segunda (variação diastrática), em especial fisgada pelo parâmetro da chancela - ou não - da cultura, ou seja, do trato dos falantes com "cultura" (o que em última análise se representa na escolarização batizada na literatura).

E acresça-se que tudo isso é válido na modalidade escrita (com o apanágio dos “escritores") mas também na modalidade oral, de que Celso Cunha não descuidou, e, nesse particular, cabe referir seu papel na história do Projeto NURC, bem como sua obra A questão da norma culta brasileira $(1985)^{5}$. Quanto à variação diacrônica, a posição assumida por nosso gramático é, pelo contrário, segregadora, com uma valorização inquestionável do moderno, e por aí é que fica caracterizada a ação escolar como ponto de chegada dos objetivos do ensino de língua (e, consequentemente, de gramática), com atenção para a variedade dialetal e a língua falada (não sem razão, especificamente a norma culta; e não sem cuidar dos perigos do "fracionamento da unidade linguística da própria nação" [CUNHA, 1985, p. 75 - ver nota]), ponto em que, justamente, ficava estabelecido o papel do ensino escolar como ação preventiva. Trata-se, pois, da "inteireza" na "pluralidade", para usar os termos de Ivan Russeff (2003, p.3).

Como se tem desenvolvido neste texto, a proposta de Celso Cunha para o trato da língua nacional / materna na ação escolar não abriga o conformismo subserviente colonialista, mas também não o nacionalismo descabido, nem ainda a fuga por expedientes simplesmente paliativos, indefinidos e descompromissados. "Preconceitos historicistas ou nacionalistas" são ambos recusados por Celso Cunha, e, a partir daí, também são recusados rótulos como "língua brasileira" (por ser jacobino), "dialeto brasileiro" (por ser subserviente) e "língua" ou "idioma" "nacional" (por ser neutro e anódino, para a língua falada em um país) (CUNHA, 1985, p.15).

Lembrando a condição de "condôminos do idioma" que foi a que Celso Cunha atribuiu a todos os falantes pareados no uso do idioma (CUNHA, 1975, p. 41), é muito lúcido que aos professores seja sugerido verem-se como os zeladores naturais desse condomínio, e até como síndicos (cada um deles um síndico), na gestão contínua desse que é bem comum de todos, pela pertença do uso e pela comunidade do convívio em troca constante.

Afinal, esse é o papel histórico que se tem o dever de atribuir a Celso Cunha, com sua firme lição sobre a defesa do equilíbrio entre tradição e modernidade, afinal o universo dentro do qual as línguas contam a sua história.

Tanto em A questão da norma culta brasileira (1985) quanto em Lingua portuguesa e realidade brasileira, (1968) e também em Que é um brasileirismo? (CUNHA, 1987), vê-se Celso Cunha dedicado ao projeto NURC (de descrição da variante brasileira culta do português). Por outro lado, em Uma política do idioma (1964), estão orientações para a pesquisa e o ensino da língua falada, com a consideração de tratar-se de país largamente "analfabeto". 
NEVES, M. The grammarian Celso Cunha: the Portuguese language, "one on diversity". Alfa, São Paulo, v.65, 2021.

- ABSTRACT: The present incursion into Celso Cunha's work highlights any tensions that he succeeds in establishing and conciliating in his linguistic-philological works. The incursion follows a notion that, with no conformity or nationalism, emerges from Cunha's proposal according to which the prominence of "cultured norm" smoothly coexists with the prominence of spoken language. This coexistence is equated in a proposal of action at school level that provides the students constructive experiences toward the apprehension of the "prestigious dialect", without being required from them the abandonment of the vernacular (and safeguarded the attention toward register adequacy). In this direction, this paper highlights, at its crux, the proposal that the work with grammar at school level should be conducted by the notion that a language is "one in diversity", given that, scientifically, any natural language is "one", nevertheless in the necessary plurality of uses (of modes of expression). In Cunha's perspective, inside this building of conciliated tensions, we all are "tenants of the language"; and given the tasks he suggests for working with the language, it is safe to understand that we ought to be natural "keepers" of this common patrimony.

- KEYWORDS: Natural language; standard norm; linguistic unit; linguistic diversity; school grammar.

\section{REFERÊNCIAS}

COSERIU, E. Sincronía, diacronía y historia: El problema del cambio lingüístico. Montevidéu: Gredos, 1958.

CUNHA, C. Que é um brasileirismo?. Rio de Janeiro: Tempo Brasileiro, 1987.

CUNHA, C. A questão da norma culta brasileira. Rio de Janeiro: Tempo Brasileiro, 1985.

CUNHA, C. Uma política do idioma. 3. ed. Rio de Janeiro: Tempo Brasileiro, 1975.

CUNHA, C. Gramática do Português Contemporâneo. Belo Horizonte: L\&PM Pocket, 1970.

CUNHA, C. Língua portuguesa e realidade brasileira. Rio de Janeiro: Tempo Brasileiro, 1968.

CUNHA, C.; Lindley CintRA, L. F. Nova Gramática do Português Contemporâneo. 2. ed. Rio de Janeiro: Nova Fronteira, 1985.

HOUAISS, A. Uma obra: a propósito de Celso Cunha. In: PEREIRA, C. C.; PEREIRA, P. R. D. (org.). Miscelânea de estudos linguísticos, filológicos e literários in memoriam Celso Cunha. Rio de Janeiro: Nova Fronteira, 1995. p. XLVII-LVI. 
MONTELlO, J. Mestre Celso Cunha. In: PEREIRA, C. C.; PEREIRA, P. R. D. (org.). Miscelânea de estudos linguísticos, filológicos e literários in memoriam Celso Cunha. Rio de Janeiro: Nova Fronteira, 1995. p. LVII-LIX.

NASCENTES, A. Estudos filológicos. Rio de Janeiro: Academia Brasileira de Letras, 2003.

NEVES, M. H.M. Em defesa das letras vivas. Folha de S. Paulo, São Paulo, p.14-15, 2004. Caderno Mais!.

PEREIRA, C. C. (org.). Sob a pele das palavras: Dispersos. Rio de Janeiro: Academia Brasileira de Letras; Ed. Nova Fronteira, 2004.

RUSSEFF, I. O ensino da Língua Portuguesa: variações em torno da "gramatiquinha brasileira". In: ANPED, 26., 2003, Poços de Caldas. Anais [...], Rio de Janeiro, v.I, p.1-9, 2003.

Recebido em 23 de julho de 2019

Aprovado em 17 de junho de 2020 